\title{
DESCRIPTION OF THE BRACKET CHAIRS FOR SUSPENDING DOUBLE-HEADED RAILS ON THE WEST CORNWALL RAILWAY.
}

By Mr. JAMES D. SHERIFF, OF TRURo.

In the Chairs ordinarily used for Double-headed Rails the rail rests entirely upon the bottom, and in consequence of the bearing surface being small the bottom head of the rail becomes indented; and by the time the top head has been worn so far as to require the rail to be turned, the indentations of the bottom head are often found to be so considerable as to prevent the rail being used when turned. The special advantage intended to be obtained with the double-headed rail, namely the power of turning it and getting a second period of wear out of the lower head, is thus lost; and the double-headed rail has consequently been abandoned in several cases for the single-headed rail, which is an inferior form as regards distribution of material for strength, and also as regards durability wherever both heads of the double-headed rail can be used. The importance of preserving the donble-headed rail from wear of the bottom head has led to the trial of several plans for suspending the rail in the chair by giving it a bearing only under the upper head, a moveable jaw being fitted into the chair for this purpose, in place of the wood key employed in the ordinary chairs. The plan that continues almost universally in use however is the original mode of carrying the rail upon the bottom of the chair, or upon a piece of hard wood placed on the bottom of the chair.

A form of chair bas long been in general use throughout the West Cornwall Railway, which carries out the principle of suspending a double-headed rail in a very efficient and satisfactory manner, and is found to have an advantage in simplicity and economy of construction, and in freedom from jar or hardness of the road in travelling. 
This Chair is shown in Figs. 1 to 3, Plate 76, and consists of two independent half-chairs or brackets, of nearly similar form, fitting close to the underside of the upper head of the rail, and extending down below the rail without any bottom to the chair underneath the rail. The chair is made high enough to raise the bottom of the rail 1-32nd inch clear above the sleeper, as seen in Fig. 2. The two halyes of the chair are secured by a $1_{1^{\frac{1}{6}}}$ inch bolt passed through the rail, with a nut on the inner side; the nut is held from turning by dropping into a recess in the chair, and the bolt is screwed up by the head. The bolts of these chairs are found to require tightening up a few times after first laying the rails, and they become then very secure, and give but little trouble afterwards by working loose. The two half-chairs are not exactly alike, and have the cheeks inclined so as to give the rail an inclination of 1 in 20 inwards.

The chair is secured to the sleeper by screwed spikes or fang bolts, and the spike hole through the inner half of the chair is slotted, as shown in the plan, Fig. 3 , to allow that half of the chair to be drawn back sufficiently for taking out the rail, if required, without withdrawing the spike. The chair is prevented from shifting in regular work by the slot being blocked with a circular washer, which fits in a recess at the end of the slot, and is kept down by the head of the spike.

The writer believes that this chair was designed by Mr. Brunel in 1858, and was first used by him on the Vale of Neatb Railway. It was also laid by him and Mr. Brereton on the Llynvi and Ogmore, the South Wales Mineral, and the Briton Ferry Dock Railways. It was adopted on the West Cornwall Railway in 1862, and by 1866 the whole of the line was relaid with these chairs, except on the viaducts where the longitudinal system is more suitable. The specimen chairs now exhibited were some of the first laid, and have been in use on the main line for eleven years.

There has now been fifteen years' experience of the working of these chairs, during which time they have undergone no apparent deterioration, and the writer has never heard of any accident having 
happened through their failure. The first lot of chairs laid on the West Cornwall Railway in 1862 were not quite so high as they should have been, and allow the lower head of the rail to touch the sleeper; but a large number of these rails have now been turned, and in no case has the lower head been found to be injured. No instance bas occurred of a sleeper breaking under the rail, nor has any indication been observed of a tendency in that direction. The result has been thoroughly satisfactory as regards durability, safety, and economy of maintenance.

The shortness of the leverage at which the strain acts upon the chair reduces materially the risk of fracture; and there is a striking difference in this respect in comparison with the large number of broken chairs that occur from driving the wood keys in the ordinary construction of chair. The division of the chair into two separate portions gives an elasticity to the support of the rail, which makes the road soft and easy for travelling; and this construction is free from the risk of a rail getting displaced by the loss or slackness of a key. The union between the rail, chair, and sleeper, is so good that there is no beating motion between them, and in the event of any movement consequent upon loose ballast the whole moves as one piece.

These chairs contain much less weight of metal than the ordinary form, as there is not any metal beneath the bottom of the rail, and no strength is required in the chair to resist the ordinary strain of keying. These chairs consequently weigh only $17 \frac{1}{2} \mathrm{lbs}$. each, instead of from 28 to $42 \mathrm{lbs}$, making the weight per mile only 29 tons instead of 69 tons, or a difference of 40 tons, which, after allowing for bolts in the one case and wedges in the other, gives a saving at present prices of $£ 382$ per mile of single line.

A specimen was exhibited of the bracket chairs which had been in use on the main line for eleven years, being some of the first that had been laid down on that line. 
The President mentioned that the paper just read had been prepared for the recent Cornwall Meeting of the Institution, at which many of the Members had had the opportunity of seeing the chairs in use on the West Cornwall line. Unfortunately Mr. Sheriff was unable to attend the present meeting, but he had sent the specimen exhibited of the chair. There might be considerable doubt felt by some as to whether the construction now shown was free from objection; and he should be glad to hear opinions upon this subject.

Mr. C. E. Axos said that from a purely mechanical point of view the construction of the bracket chair appeared to him to be an advantageous one, and he thought it was calculated to realise all the advantages that were attributed to it. In regard to the circumstance mentioned in the paper, that the tie bolt uniting the two halves of the chair was screwed up by the head, while the vut was held from turning by fitting into a recess in the chair, he did not see how this was an advantage over the ordinary plan of turning the nut; for he thought, if there were any tendency to shake loose, the bolt was likely to get loose as easily when screwed up by the head as when tightened by turning the nut. Considering however that the whole was screwed up tight, metal to metal, he thought there was very little chance of its shaking loose or causing any trouble, whichever mode of screwing up was adopted.

Mr. W. E. Newron thought this simple construction of chair was calculated to achieve success, because a great many of the breakages in the ordinary construction of chair arose from the expansion of the wood keys by the absorption of moisture. It was well known that the force exerted by wood swelling through absorption of moisture was exceedingly great, so that it could be employed even for bursting masses of rock in quarrying operations. It was therefore not surprising to find that a great many of the ordinary solid cast-iron chairs had been burst by the expansion of the wood keys; and the bracket chair now described was evidently not only a much cheaper construction, but was also calculated, he considered, to obviate that difficulty. 
The President observed that one point to be noticed with regard to this construction of chair was that the rail was perforated by a large hole at each chair; and though this would not be a serious objection with a rail having a rigid bearing on the bottom, as in the ordinary chairs, he thought it would be a considerable drawback in the present case of a suspended rail, by weakening the rail in its continuity. It was remarkable how much a rail was weakened by such a hole being made through it, especially a steel rail. Having had occasion lately to make some experiments on this subject, he had found that, while a sound steel rail laid across bearings 3 feet apart would bear repeated blows of a ton weight falling upon it from a height of 20 feet without giving way, a piece of the same rail laid across the same bearings with only an inch hole punched through the centre and midway between the supports broke with a single blow of a ton weight falling on it from only 6 feet height, showing how greatly the rail was weakened by the perforation. This seemed to indicate that chairs which did not involve the necessity of perforating the rail would be preferable. There were however many compensating advantages in the bracket chair now described, particularly the absence of any bursting pressure upon the chair ; and the experience already gained of it was a considerable proof in its favour.

Mr. D. Halpin asked whether the President's experiments on the effect of perforating rails had been extended to the difference between drilled and punched holes, which was a question that had recently arisen in connection with rails used on the Metropolitan Railway.

The President replied that it had made hardly any difference in the strength of the rail whether the hole were punched or drilled; and he thought that would always be the caso if the material was good and tough.

Mr. C. C. WALKER considered it a very important fact which had been stated, that in good material the metal was not weakened more by punching than by drilling.

Mr. C. E. Amos said he entirely concurred in that statement; but he was surprised to hear that a steel rail was so much weakened as had been mentioned by simply perforating it with a small hole, 
and he considered under the same conditions a good wrought-iron rail would hardly have been injured by the hole, and would not have been nearly so easily broken. It appeared to him there was yet much to be learnt in regard to the nature and properties of steel, notwithstanding the experience hitherto gained from its use, and the very numerous experiments made upon it. It seemed to be less reliable in strength than wrought iron, for he had seen some steel bars when tested give way at once without any alteration in section at the point of fracture, while others would only yield after having undergone considerable alteration, thus exhibiting a remarkable variation in strength in different makes of steel.

Mr. C. C. WALKER mentioned that in some experiments he had lately made upon the breaking strain of cast-iron bars, of 2 inch by 1 inch section and supported upon bearings 3 feet apart, he had found that, while such a bar of the toughest and strongest cast irou would bear a dead weight of 32 or even $33 \mathrm{cwts}$. before breaking, yet the blow of a $21 \mathrm{lbs}$. hammer falling from a height of only 15 ins. or even 12 ins. would break it. On the other hand, another bar of a different quality of cast iron, which would bear a dead weight of only 23 or even only $21 \mathrm{cwts}$, required a blow from the same hammer falling 24 ins. or even 28 ins. to break it. This showed plainly that the cast iron which proved the strongest under the test of a dead weight, and was in such particular request for bridges and girders, was really often the weakest to withstand a blow; and cast iron which was weaker under a dead weight would require a much greater force of blow to break it. Moreover the iron that bore the greatest dead weight was not only broken by a lighter blow, but was broken into several pieces by the blow. It therefore appeared to him a great mistake to regard only the test of a dead weight for cast-iron structures that were required to resist a blow as well as a dead weight; and he considered the strength of the iron under a blow should also be taken into account.

Mr. C. E. Amos observed that an analogous case was that of earthenware, which would bear a considerable dead load, but if let fall would break readily. At Messrs. Maudslay's works he understood it had for many years past been the practice to select all 
the cast iron employed there by casting a sample bar of given section and length, and laying it across bearings fixed for the purpose, and then dropping a given weight upon it from a given height; if the bar bore that blow without breaking, the iron was considered to be of the required strength.

Mr. D. Halpin suggested that in testing cast iron by the blows of a falling weight it would be desirable to agree npon some standard of comparison; and the best iron would then be that which bore the greatest number of blows of given force before breaking. Under a dead weight too, some bars might bear a very great load and then yield suddenly at last, while others would give way more gradually under a smaller load, showing a great difference as regarded the work done upon the iron in effecting its fracture.

The Presiden' considered it must not be concluded that steel was not a reliable material, on account of the great difference in the results in testing different bars. No doubt a bar of one sort of steel would break like a piece of pottery ware, while another of a different sort could not be broken by any number of blows, even though turned over and struck alternately npon opposite sides. But in order to understand why in one case a bar of steel broke and in another case did not break, and why a piece of steel which would bear one sort of strain would not stand another, it was necessary to take into consideration the chemical composition of the different kinds of steel. A bar of steel containing a considerable percentage of carbon would not stand a moderate blow from a falling hammer, but would stand a greater dead weight than a bar which would not break under the blow of the hammer; whilst on the other hand a bar that would resist the blow of the falling weight would not sustain so great a dead load. There was a difference between mild steel and wrought iron in this respect, namely that steel would bear a constant and gradual strain much better than iron, whereas iron would not give way under a sudden strain so readily as steel, particularly if the form were jrregular in both cases. And this he thought was a necessary consequence of the homogeneous character of steel, owing to which, if a sudden strain came upon it, the weakest section at once received that strain entirely, there being 
no fibres to take the strain one after another, and therefore if the strain were excessive the steel would give way by tearing like paper; whereas with wrought iron, although it might be distorted by a sudden strain, yet each fibre would not break at the same moment, and thus an iron bar would not be broken by a blow which would break a steel bar. It was this property of steel which rendered it wholly inapplicable for armour-plating; but it was no reproach to steel to say that under certain conditions it would break more readily than wrought iron, considering that under other conditions it bore much higher strains and was more reliable.

He moved a vote of thanks to Mr. Sheriff for his paper, which was passed.

The following paper was then read:- 
Fig: 1. Side Elevation.
